\title{
Clinical Characteristics and Prognostic Factors in Pediatric Vascular Tumors
}

This article was published in the following Dove Press journal:

Pediatric Health, Medicine and Therapeutics

Piya Rujkijyanont (ID)

Chanchai Traivaree (D)

Kantang Satayasoontorn (iD ${ }^{2}$

Apichat Photia $\mathbb{D}^{\prime}$

Nawachai Lertvivatpong'

Chalinee Monsereenusorn $\left(\mathbb{D}^{1}\right.$

'Division of Hematology/Oncology,

Department of Pediatrics,

Phramongkutklao Hospital and

Phramongkutklao College of Medicine,

Bangkok, Thailand; ${ }^{2}$ Department of

Pathology, Phramongkutklao Hospital and

Phramongkutklao College of Medicine,

Bangkok, Thailand
Correspondence: Chalinee

Monsereenusorn

Division of Hematology/Oncology,

Department of Pediatrics, Phramongkutklao

Hospital and Phramongkutklao College of

Medicine, 315 Ratchawithi Road

Ratchathewi, Bangkok, 10400, Thailand

Email chalinee_monsereenusorn@pedpmk.

org
Background: The most common type of vascular tumors reported among children is hemangioma. The determinant factors to predict clinical outcomes among those patients were not well studied.

Objective: The study aimed to explore clinical characteristics and treatment approaches as well as associated prognostic factors of vascular tumors specifically in a pediatric population. Methods: Pediatric patients with a confirmed diagnosis of vascular tumors between January 1, 2005 and December 31, 2017 were enrolled in this study. Clinical data includes initial clinical manifestations with associated complications, and diagnostic studies were used. To establish a diagnosis, the treatment modalities provided and final outcomes were retrospectively reviewed and analyzed.

Results: In all, 50 patients with a confirmed diagnosis of vascular tumors were enrolled. The median age at diagnosis was 11.5 years with equal gender distribution. The most common type of vascular tumor was hemangioma $(n=41,82 \%)$, followed by pyogenic granuloma $(\mathrm{n}=4,8 \%)$, kapasiform hemangioendothelioma with Kasabach-Merritt phenomenon $(\mathrm{n}=2$, $4 \%)$, infantile hepatic hemangioma $(n=2,4 \%)$, and juvenile nasal angiofibroma $(n=1,2 \%)$. The median age at diagnosis among patients with cutaneous vascular tumors ( 12.4 years) was significantly older than the age of those with visceral vascular tumors (1.3 years) with $a P$-value of 0.009 . The mean size among patients with visceral tumors (7.46 $\pm 4.84 \mathrm{~cm})$ was significantly greater than the size among patients with cutaneous tumors $(3.21 \pm 3.7 \mathrm{~cm})$ with $a P$-value of 0.023 . The size of the tumor was the only independent risk factor associated with clinical outcomes.

Conclusion: Age at diagnosis in cutaneous vascular tumors was significantly older than in visceral vascular tumors. Clinical outcomes are favorable among most patients and the size of the tumors is an independent risk factor associated with outcomes.

Keywords: pediatric, vascular tumor, prognostic factor, size, outcome

\section{Background}

Among various types of vascular tumors, including hemangioma, tufted angioma, pyogenic granuloma, kapasiform hemangioendothelioma (KHE), and infantile hepatic hemangioma, the most common type of vascular tumors reported among children is hemangioma, with an incidence of $3-10 \%$ among infants. ${ }^{1}$ There are currently several different types of hemangiomas, as classified by the International Society for the Study of Vascular Anomalies (ISSVA). ${ }^{2}$ However, clinical manifestations of hemangioma depend on the depth of the tumor as well as its location. Internal organ hemangioma or hemangioma with visceral involvement usually occurs less commonly ${ }^{3}$ among patients with multiple hemangiomas. ${ }^{4}$ Visceral 
hemangioma is generally associated with various complications, including high output cardiac failure, compartment syndrome, hemorrhage, gut obstruction and perforation, as well as coagulopathy. ${ }^{3}$ Kasabach-Merritt phenomenon (KMP), a crucial complication which carries a high mortality rate, consisting of thrombocytopenia and consumptive coagulopathy, is associated with specific vascular tumors such as tufted angioma and kapasiform hemangioendothelioma. ${ }^{5}$

History taking and physical examination are a fundamental approach to diagnose and specify the types of vascular tumors. Additional investigations including a radiological study or tissue pathology might be needed in certain circumstances of equivocal cases. Management approaches of vascular tumors are varied including solely observation, ${ }^{6}$ use of medication or local therapy, and surgical excision of the tumor. A surgical approach is indicated among those patients who experience severe symptoms or cosmetic issues related to the tumor or those whose malignant etiology could not be entirely ruled out. ${ }^{7}$ Medical approaches of vascular tumors including intralesional or systemic corticosteroid, ${ }^{8}$ interferon- $\alpha$, vincristine, ${ }^{9}$ or a combination of vincristine and prednisolone, ${ }^{8}$ oral propranolol, ${ }^{10-12}$ sirolimus, ${ }^{13}$ and laser therapy ${ }^{14}$ have also been reported and used among those patients who have unresectable tumors with complications.

Outcomes of vascular tumors are heterogenous, ranging from spontaneous regression without residual skin lesions to less than $30 \%$ of the 5 -year overall survival rate in vascular tumors with a malignant pattern of angiosarcoma. ${ }^{15}$ Prognostic factors associated with outcomes in vascular tumors are not well addressed in most related literature. Resectability and successful wound closure with or without skin graft $^{16}$ were reported and could potentially serve as a predictor to achieve disease remission.

The most recent published data was from North America $^{11}$ and European populations. ${ }^{17,18}$ There were few studies from Asia-Pacific populations. ${ }^{19,20}$ Herein, this study is the very first study aimed to explore clinical characteristics including investigational and treatment approaches as well as associated prognostic factors of vascular tumors specifically in a pediatric population in South-East Asia.

\section{Patients and Methods}

\section{Patient Selection}

Fifty-five pediatric patients who were primarily clinically suspected of vascular tumors from the Department of
Pathology combined with patients who were followed at the Division of Hematology and Oncology, Department of Pediatrics, Phramongkutklao Hospital from January 1, 2005 to December 31, 2017 were retrospectively reviewed. Written informed consent and assent forms to take part in the study were obtained from all participants including the children themselves as well as their parents or legal guardians before collecting the patient's clinical data. This retrospective study was approved by the Institutional Review Board, Royal Thai Army Medical Department according to the ethics principles of the Declaration of Helsinki (1975) and its revision (reference number: IRBRTA 959/2562). The study was also registered and approved by the Thai Clinical Trials Registry (TCTR20190917001). The study's inclusion criteria included patients from birth to 21 years old for whom the diagnosis of vascular tumors was confirmed by histopathological or radiological findings and were treated at the Division of Hematology and Oncology, Department of Pediatrics, Phramongkutklao Hospital. Patients with an uncertain diagnosis, incomplete medical records, or not being treated primarily at Phramongkutklao Hospital were excluded from the study.

\section{Institutional Diagnostic Guidelines of Vascular Tumors}

The institutional diagnostic guidelines for each specific type of vascular tumors were described as follows: hemangioma was diagnosed using either histopathological findings or radiological imaging of doppler or magnetic resonance imaging (MRI)-T2 weighted images. Cutaneous vascular tumor was confirmed by visible evidence of a vascular mass or histopathological confirmation in the case of any other vascular lesions located in superficial or within the deep dermis or subcutis layer of skin. Visceral vascular tumor was defined by evidence of a vascular mass or lesion located at internal or visceral organs such as the liver, brain, orbit, gastrointestinal tract, or retroperitoneal space. Pyogenic granuloma was confirmed by histopathological examination. KHE and liver hemangioendothelioma or infantile hepatic hemangioma were diagnosed using radiological imaging, preferably MRI-T2 weighted images. KMP was defined as hemangioma of cutaneous or internal organs with evidence of thrombocytopenia (platelet count less than $50,000 / \mathrm{mm}^{3}$ ) and consumptive coagulopathy, in which other causes for the abnormalities were excluded such as immune 
thrombocytopenia (ITP), etc. Lastly, juvenile nasal angiofibroma (JNA) was diagnosed by histopathological examination.

\section{Treatment Response Criteria}

Complete remission or resolution was defined as resolution of all signs and symptoms, all laboratory parameters returning to normal level for age and unrequired blood transfusion.

Partial remission or resolution was defined as regression of signs or symptoms, no new lesions, improved laboratory parameters but without completely returning to normal level for age, and/or requiring fewer transfusions.

\section{Statistical Analysis}

Baseline values of selected variables, such as demographic data, clinical manifestations, diagnostic studies, treatment strategies, complications, and outcomes from all participating patients were analyzed using descriptive statistics and presented as mean with standard deviation (SD) or as median (range) for continuous variables and were calculated using frequency and percentage for categorical variables. Categorical and continuous variables were compared using Chi-square or Fisher's exact tests and independent sample $t$-test, respectively. Univariate and multivariate binary logistic regression analyses were performed to analyze the impact of possible factors on defined outcomes. Statistical analysis was performed using IBM SPSS Statistics for Windows, Version 23.0 (IBM Corp., Armonk, NY, USA). A $P$-value $<0.05$ was considered statistically significant.

\section{Results}

\section{Patient Characteristics}

Among 55 patients who were clinically suspicious for vascular tumors and/or obtained the pathology tissue at the Department of Pathology and were treated primarily at the Division of Hematology and Oncology, Department of Pediatrics, Phramongkutklao Hospital, five patients were excluded due to the final diagnosis confirming nonvascular tumors, incomplete data sets, or lost to follow-up. Therefore, 50 patients with a confirmed diagnosis of vascular tumors were subsequently enrolled in this study, as shown in Figure 1. Medical records of all participating patients were retrospectively reviewed, with complete information described in Supplementary Table 1. Patients' characteristics, including age, sex, diagnosis, diagnostic modalities, including histopathological examination and imaging studies, size and location of the tumors, treatment strategies and their complications, and clinical outcomes are summarized in Table 1.

Among 50 patients with vascular tumors enrolled in this study, most presented as older age with a median age at diagnosis of 11.5 years and sex equally distributed. Hemangioma was the most common diagnosis followed by pyogenic granuloma, KHE with KMP, infantile hepatic hemangioma or liver hemangioendothelioma without $\mathrm{KMP}$, and juvenile nasal angiofibroma (JNA), in rank. Histopathological examination was the key diagnostic modality to establish the diagnosis, with radiological studies required in small numbers of patients whose tumors were inoperable. The reasons for the inability to resect the tumors were large hemangiomas at the face and lower extremity on two patients, tumor with KMP-related complications on two patients, and multiple infantile hepatic hemangiomas on one patient.

The average tumor size was $3.6 \mathrm{~cm}$ in the longest diameter located most commonly at the head and neck regions, including the scalp, eyelids, face, and lips. Most patients presented cutaneous vascular tumors, in which only $10 \%$ were noted to have visceral tumors located at the liver, brain, orbit, and retroperitoneal regions. Hemorrhagic complications were commonly seen at initial diagnosis, followed by poor weight gain, proptosis, feeding intolerance, and seizures, in rank.

\section{Radiological Studies}

Among 50 patients with vascular tumors enrolled in this study, radiological studies were essentially required to assist in establishing diagnosis and management plans in

Assessed for eligibility $(n=55)$ Patients with clinically suspicious for vascular tumors were reviewed

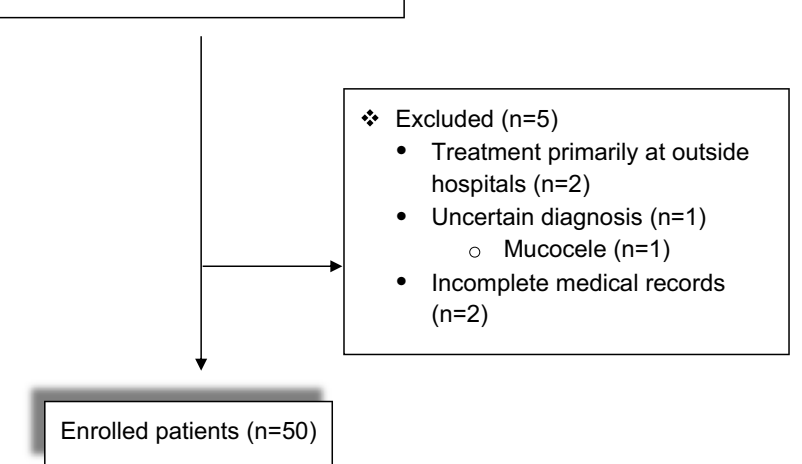

Figure I Study flow diagram. 
Table I Patients' Demographic Data $(n=50)$

\begin{tabular}{|c|c|c|}
\hline \multicolumn{2}{|c|}{ Demographic Data } & \multirow{2}{*}{$\begin{array}{l}\mathbf{N}(\%) \\
11.5(0-18.58) \\
10.36 \pm 5.36\end{array}$} \\
\hline $\begin{array}{l}\text { Age at diagnosis } \\
\text { (years) }\end{array}$ & $\begin{array}{l}\text { Median (range) } \\
\text { Mean } \pm \text { SD }\end{array}$ & \\
\hline Gender & $\begin{array}{l}\text { Male } \\
\text { Female }\end{array}$ & $\begin{array}{l}25(50) \\
25(50)\end{array}$ \\
\hline Diagnosis & $\begin{array}{l}\text { Hemangioma } \\
\text { Pyogenic Granuloma } \\
\text { Kapasiform } \\
\text { hemangioendothelioma with KMP } \\
\text { Infantile hepatic hemangioma* } \\
\text { Juvenile nasal angiofibroma }\end{array}$ & $\begin{array}{l}4 I(82) \\
4(8) \\
2(4) \\
2(4) \\
I(2)\end{array}$ \\
\hline $\begin{array}{l}\text { Diagnostic } \\
\text { modality }\end{array}$ & $\begin{array}{l}\text { Tissue diagnosis } \\
\text { Radiological diagnosis }\end{array}$ & $\begin{array}{l}45(90) \\
5(10)\end{array}$ \\
\hline Size $(\mathrm{cm})$ & $\begin{array}{l}\text { Median (range) } \\
\text { Mean } \pm \text { SD }\end{array}$ & $\begin{array}{l}1.5(0.3-16) \\
3.66 \pm 4.00\end{array}$ \\
\hline Location & $\begin{array}{l}\text { Head and neck } \\
\text { Extremities } \\
\text { Trunk } \\
\text { Liver } \\
\text { Intracranial } \\
\text { Retroperitoneum }\end{array}$ & $\begin{array}{l}24(48) \\
19(38) \\
3(6) \\
2(4) \\
I(2) \\
I(2)\end{array}$ \\
\hline Complication & $\begin{array}{l}\text { None } \\
\text { Bleeding } \\
\text { Poor weight gain } \\
\text { Bleeding and feeding intolerance } \\
\text { Proptosis } \\
\text { Seizure }\end{array}$ & $\begin{array}{l}39(78) \\
7(14) \\
I(2) \\
I(2) \\
I(2) \\
I(2)\end{array}$ \\
\hline Imaging & $\begin{array}{l}\text { Not done } \\
\text { Done } \\
\text { MRI } \\
\text { Multi-Modalities } \\
\text { Ultrasound } \\
\text { CT scan }\end{array}$ & $\begin{array}{l}29(58) \\
21(42) \\
8(16) \\
6(12) \\
6(12) \\
1(2)\end{array}$ \\
\hline Treatment & $\begin{array}{l}\text { Surgery } \\
\text { Medication } \\
\text { Observation }\end{array}$ & $\begin{array}{l}44(88) \\
3(6) \\
3(6)\end{array}$ \\
\hline Outcome & $\begin{array}{l}\text { Alive, no evidence of disease } \\
\text { Alive with disease } \\
\text { Deceased, no evidence of disease }\end{array}$ & $\begin{array}{l}43(86) \\
6(12) \\
I(2)\end{array}$ \\
\hline
\end{tabular}

Notes: Data are presented as mean $\pm S D$ and range (median) for continuous variables and number (\%) for categorical variables. *Infantile hepatic hemangioma means liver hemangioendothelioma.

Abbreviations: KMP, Kasabach-Merritt phenomenon; MRI, magnetic resonance imaging; $\mathrm{CT}$, computed tomography.

almost half of the patients. The most common radiological modality used in this study was MRI, followed by ultrasonography and computed tomography (CT) scans, as shown in Table 1. However, six in 21 patients required a combination of radiological imaging including CT scan, ultrasonography, Tc 99m-bone scan, and MRI. In addition, all vascular tumors with visceral organ involvement, KHE with KMP, JNA, and infantile hepatic hemangioma were imaged.

\section{Treatment Strategies}

Over $90 \%$ of the patients enrolled in this study received treatment interventions, as shown in Table 1, and most underwent surgical resection of the tumors with no postoperative complications reported. However, three patients who underwent surgery had disease recurrence after partial resection of the tumors. The remaining patients undergoing surgery remained in complete remission until their last follow-up visits. Medical treatment was administered among three patients $(6 \%)$. Intravenous vincristine combined with oral prednisolone was delivered to two patients with KHE complicated by KMP, resulting in complete resolution of the tumors. One patient received oral prednisolone monotherapy with partial response to treatment. The decision was made to closely observe and monitor clinical status among three patients $(6 \%)$ whose tumors were inoperable including the scalp hemangioma, large intramuscular hemangioma of the right leg, and multiple infantile hepatic hemangiomas. Spontaneous regression until complete resolution of the tumor was noted in one patient. However, another two experienced spontaneous regression with partial resolution of the tumor on their last follow-up visit.

\section{Treatment Outcomes}

All patients with vascular tumors enrolled in this study did not experience tumor-related mortality. Only one patient, presenting hemangioma at the extremity, which was completely excised, died of liver cirrhosis and congestive heart failure due to the underlying biliary atresia status postKasai operation. In summary, 43 patients (86\%) survived without evidence of disease. Six (12\%) patients survived with disease, including three patients who had disease recurrence after partial resection of the tumors, one who was treated with oral prednisolone with partial response, one with intramuscular hemangioma of the right leg, and one with multiple infantile hepatic hemangiomas. The last two patients were closely observed clinically, as shown in Supplementary Table 1. All patients who survived with disease had normal physical function without disease complication. 
A

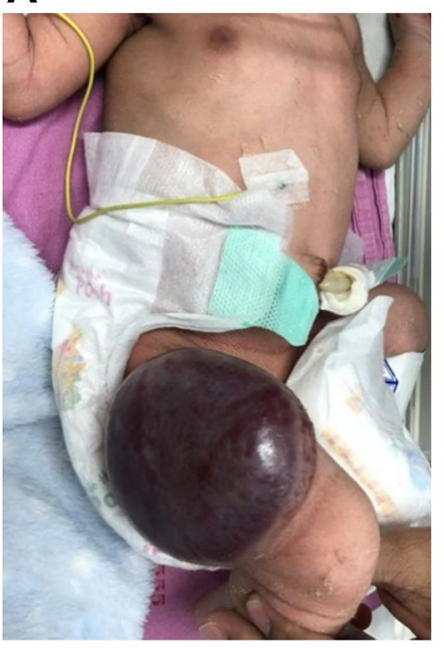

B

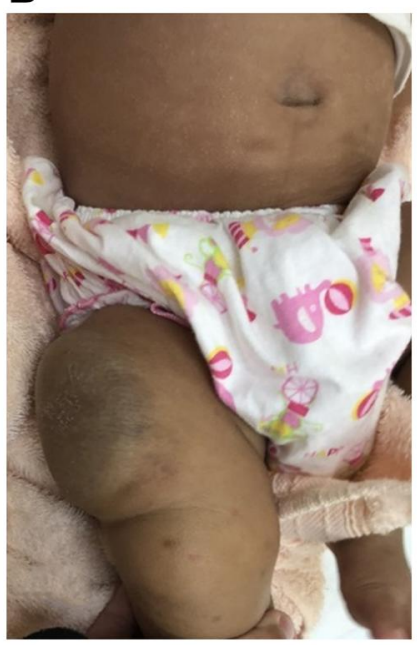

C

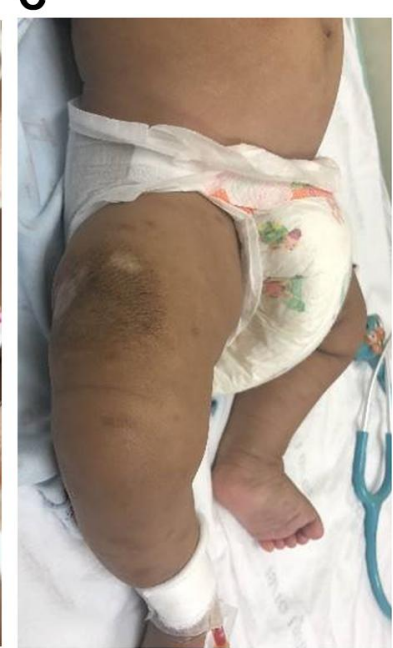

Figure 2 Newborn with kapasiform hemangioendothelioma with Kasabach-Merritt phenomenon of right leg at birth (left figure), after treatment at 4-months-old (middle figure) and at 8-months-old (right figure).

\section{Kapasiform Hemangioendothelioma (KHE) with Kasabach-Merritt Phenomenon (KMP)}

Two patients of KHE with KMP enrolled in this study received a diagnosis from clinical and laboratory findings combined with radiological studies, as described in Supplementary Table 2. Both cases required multiple platelet and cryoprecipitate transfusions to maintain platelet count as well as fibrinogen level in the normal range. In addition, intravenous vincristine and oral prednisolone were administered, resulting in complete resolution of the tumors. The first patient was treated with prednisolone $2 \mathrm{mg} / \mathrm{kg} / \mathrm{day}$ for 2 weeks and then tapering off at 6 weeks, and vincristine $0.625 \mathrm{mg} / \mathrm{kg} /$ day weekly for 4 weeks then monthly for 5 months (totaling 6-months of therapy), and the patient could achieve complete remission within 8 months after treatment (Figure 2). The second patient was also treated with combined vincristine and prednisolone regimen and could achieve complete resolution within 6 months after treatment. In addition, both patients survived without any evidence of disease recurrence.

\section{Cutaneous versus Visceral Vascular Tumors}

The majority of patients enrolled in this study presented cutaneous vascular tumors $(90 \%) ; 10 \%$ of those experienced visceral involvement. Patient characteristics include age, sex, location of the tumors, size, diagnosis, treatment strategies, clinical outcomes, and diagnostic modalities: histopathological examination, imaging studies are summarized in Table 2 . The result shows no significant difference regarding sex, treatment modalities, and outcomes between the two groups of patients. Interestingly, the median age at diagnosis of patients with cutaneous vascular tumors was significantly older than the age of those with visceral vascular tumors ( $P$-value 0.009$)$. In addition, the mean size of visceral vascular tumors among patients was significantly greater than the size of those with cutaneous vascular tumors $(P$-value $=0.023)$. Types of cutaneous and visceral vascular tumors also significantly differed, in which hemangioma, pyogenic granulomas, and JNA were found mostly among patients with cutaneous vascular tumors with a $P$-value $<0.001$. Moreover, histopathological examination was mostly performed and served as the main diagnostic modality among patients with cutaneous vascular tumors compared with those with visceral vascular tumors $(P$-value $=0.018)$.

\section{Influential Factors Associated with Clinical Outcomes}

Among 50 patients with vascular tumors enrolled in this study, 49 patients survived. Age at diagnosis, sex, location of the tumors, existing visceral involvement, and types of treatment was analyzed and found to not be significantly associated with outcomes. However, univariate analysis was performed revealing significant differences in average 
Table 2 Characteristics and Outcomes of Cutaneous vs Visceral Vascular Tumors $(n=50)$

\begin{tabular}{|c|c|c|c|c|c|}
\hline \multicolumn{2}{|c|}{ Type of Vascular Tumor Demographic Data } & \multirow{3}{*}{\begin{tabular}{l}
\multicolumn{1}{c}{ Cutaneous } \\
$(n=45) \mathbf{N}(\%)$ \\
$11.01 \pm 4.9$ \\
12.42 \\
$(0-18.58)$
\end{tabular}} & \multirow{3}{*}{\begin{tabular}{l}
\multicolumn{1}{c}{ Visceral } \\
$(n=5) \mathbf{N}(\%)$ \\
$4.52 \pm 6.37$ \\
1.25 \\
$(0.25-15.33)$
\end{tabular}} & \multirow{3}{*}{\begin{tabular}{l}
\multicolumn{1}{c}{ Total } \\
$(n=50) \mathbf{N}(\%)$ \\
$10.36 \pm 5.36$ \\
11.5 \\
$(0-18.58)$
\end{tabular}} & \multirow{3}{*}{$\begin{array}{l}P \text {-value } \\
0.009\end{array}$} \\
\hline & & & & & \\
\hline $\begin{array}{l}\text { Age at diagnosis } \\
\text { (years) }\end{array}$ & $\begin{array}{l}\text { Mean } \pm S D \\
\text { Median } \\
(\min -\max )\end{array}$ & & & & \\
\hline Gender & $\begin{array}{l}\text { Male } \\
\text { Female }\end{array}$ & $\begin{array}{l}23(92) \\
22(88)\end{array}$ & $\begin{array}{l}2(8) \\
3(12)\end{array}$ & $\begin{array}{l}25(50) \\
25(50)\end{array}$ & 0.637 \\
\hline Location & $\begin{array}{l}\text { Head and neck } \\
\text { Extremities } \\
\text { Trunk } \\
\text { Liver } \\
\text { Brain } \\
\text { Retroperitoneum }\end{array}$ & $\begin{array}{l}23(95.8) \\
19(100) \\
3(100) \\
0(0) \\
0(0) \\
0(0)\end{array}$ & $\begin{array}{l}I(4.2) \\
0(0) \\
0(0) \\
2(100) \\
I(100) \\
I(100)\end{array}$ & $\begin{array}{l}24(48) \\
19(38) \\
3(6) \\
2(4) \\
1(2) \\
1(2)\end{array}$ & $<0.001$ \\
\hline Size $(\mathrm{cm})$ & $\begin{array}{l}\text { Mean } \pm S D \\
\text { Median } \\
(\text { min-max })\end{array}$ & $\begin{array}{l}3.21 \pm 3.7 \\
1.45 \\
(0.30-16.00)\end{array}$ & $\begin{array}{l}7.46 \pm 4.84 \\
7.80 \\
(2.50-15.00)\end{array}$ & $\begin{array}{l}3.66 \pm 4.00 \\
1.50 \\
(0.30-16.00)\end{array}$ & 0.023 \\
\hline Diagnosis & $\begin{array}{l}\text { Hemangioma } \\
\text { Pyogenic granuloma } \\
\text { KHE with KMP } \\
\text { Infantile hepatic } \\
\text { hemangioma* Juvenile nasal angiofibroma }\end{array}$ & $\begin{array}{l}39(95.1) \\
4(100) \\
I(50) \\
0(0) \\
I(100)\end{array}$ & $\begin{array}{l}2(4.9) \\
0(0) \\
1(50) \\
2(100) \\
0(0)\end{array}$ & $\begin{array}{l}4 I(82) \\
4(8) \\
2(4) \\
2(4) \\
I(2)\end{array}$ & $<0.001$ \\
\hline Diagnostic modality & $\begin{array}{l}\text { Tissue diagnosis } \\
\text { Radiological diagnosis }\end{array}$ & $\begin{array}{l}42(93.3) \\
3(60)\end{array}$ & $\begin{array}{l}3(6.7) \\
2(40)\end{array}$ & $\begin{array}{l}45(90) \\
5(10)\end{array}$ & 0.018 \\
\hline Treatment & $\begin{array}{l}\text { Surgery } \\
\text { Medication } \\
\text { Observation }\end{array}$ & $\begin{array}{l}41(93.2) \\
2(66.7) \\
2(66.7)\end{array}$ & $\begin{array}{l}3(6.8) \\
\text { I (33.3) } \\
\text { I (33.3) }\end{array}$ & $\begin{array}{l}44(88) \\
3(6) \\
3(6)\end{array}$ & 0.127 \\
\hline Outcome & $\begin{array}{l}\text { Alive, no evidence of disease } \\
\text { Alive with disease } \\
\text { Deceased, from others, no evidence of disease }\end{array}$ & $\begin{array}{l}39(90.7) \\
5(83.3) \\
I(100)\end{array}$ & $\begin{array}{l}4(9.3) \\
I(16.7) \\
0(0)\end{array}$ & $\begin{array}{l}43(86) \\
6(12) \\
I(2)\end{array}$ & 0.806 \\
\hline
\end{tabular}

Notes: Data are presented as mean \pm SD and range (median) for continuous variables and number (\%) for categorical variables. Comparison between two independent data sets were analyzed using Fisher's exact test, Chi-square test or Independent Sample $t$-test (age at diagnosis and size). $P$-value $<0.05$ is considered as statistical significance. *Infantile hepatic hemangioma means liver hemangioendothelioma.

Abbreviations: KHE, kapasiform hemangioendothelioma; KMP, Kasabach-Merritt phenomenon.

tumor size between patients who survived with residual disease $(8.8 \pm 4.64 \mathrm{~cm})$ and those who survived without disease $(2.96 \pm 3.37 \mathrm{~cm})$, with a $P$-value of 0.008 . In addition, multivariate analysis was subsequently performed affirming that the size of vascular tumor remained an independent risk factor to identify the outcome of disease with a $P$-value of 0.008 , as shown in Table 3 (adjusted odds ratio $[\mathrm{OR}]=1.359 ; 95 \%$ confidence interval $[\mathrm{CI}]$ $=1.083-1.707$ ).

Moreover, among 44 particular patients with cutaneous vascular tumors who survived, age at diagnosis, sex, and types of treatment were not significant predicting factors for the outcomes. However, univariate analysis was performed revealing statistically significant differences of average tumor size between patients who survived with residual disease $(9.00 \pm 5.15 \mathrm{~cm})$ and those who survived without disease $(2.46 \pm 2.73 \mathrm{~cm})$ with a $\mathrm{P}$-value $<0.001$. In addition, multivariate analysis was subsequently performed affirming that the size of vascular tumor remained an independent risk factor to identify the outcome of disease, particularly among patients with cutaneous vascular tumors with $a p$-value of 0.027 , as shown in Table 4 (adjusted OR $=1.487 ; 95 \%$ $\mathrm{CI}=1.046-2.116$ ). 


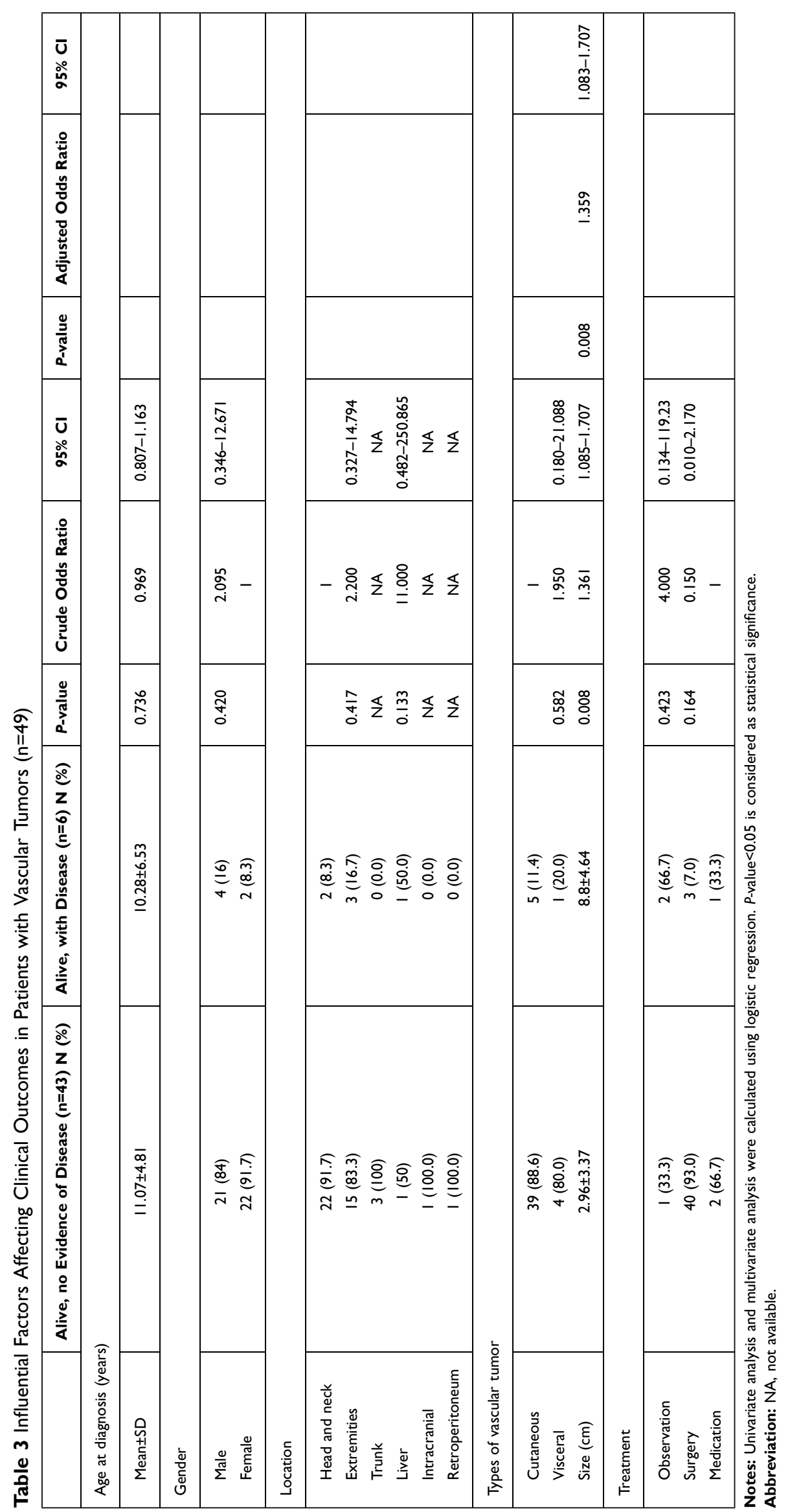




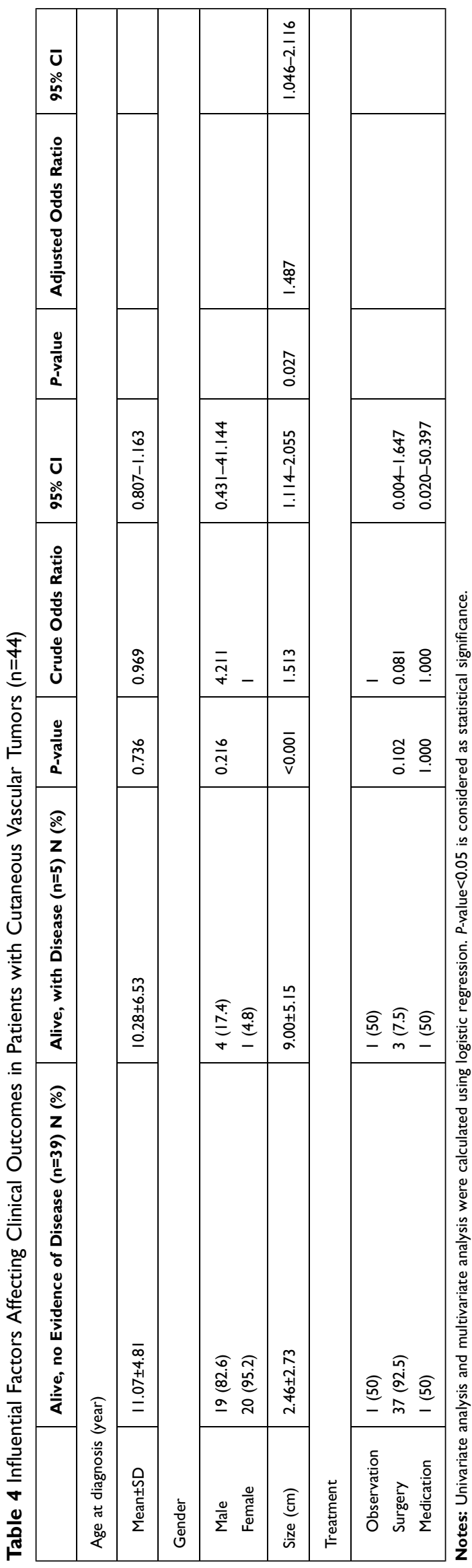

\section{Discussion}

The most common type of vascular tumors is hemangioma. ${ }^{21}$ Although approximately $90 \%$ of hemangiomas spontaneously resolve without complications, location of the tumors, and depth of the lesions or visceral involvement are determinant factors associated with complications including ulceration, visual compromise, airway obstruction, bleeding, infection, high output congestive heart failure, and other cosmetic issues. ${ }^{22,23}$ In our study, the hemorrhagic issue was the most common complication associated with vascular tumors in the pediatric population, followed by poor weight gain, feeding intolerance in KHE with KMP, proptosis, and seizure in a case of intracranial hemangioma.

There were documents of the relationship between races, ethnicities, and incidence of hemangiomas. Infantile hemangioma is typically found during infancy with an incidence of $4.5 \%{ }^{24}$ and an increasing trend in Hispanic children in the United States, ${ }^{25}$ while the approximate incidence rate in a Dutch population was $9.9 \%,{ }^{17}$ compared to Asians at 1 per 125 persons per year. ${ }^{12}$ Median age at diagnosis of vascular tumor was 11.5 years in our study. This explained from patients' enrollment in this study was patients underwent surgery, treated, and followed at the Pediatric Hematology and Oncology setting. These patients were of older age and had resectable disease.

One of the key elements for treating vascular tumors is surgical resection. In this study, almost $90 \%$ of patients underwent complete surgical resection of the tumors. However, the decision to select types of treatment modality for hemangioma was precautionary, based on the risk of distinct permanent cosmetic disfigurement or the presence or likelihood of complications. ${ }^{22}$ Because of morbidities and complications associated with surgical intervention and the benign nature of the disease, close observation with serial follow-up and imaging surveillance might be preferable, especially in noncomplicated or difficult cases with inoperable tumors. In this study, spontaneous regression until complete resolution of the tumor was observed in one patient, and two patients had partial resolution. Oral propranolol, ${ }^{11,12,26}$ intravenous vincristine $^{9}$ with or without oral corticosteroid, ${ }^{26}$ laser, sclerotherapy, and embolization ${ }^{27}$ have been implemented as alternative treatments in complicated unresectable hemangiomas. A combination of intravenous vincristine and oral prednisolone could successfully induce KHE 
complicated by KMP to complete remission for two patients, and another patient who received oral prednisolone monotherapy had a partial response to treatment.

Visceral vascular tumor is a unique entity of vascular tumors, in which the nature of the disease varies from an indolent clinical course in small sized tumors at an invisible location to catastrophic features in large tumors, along with serious complications from visceral involvement. Chang et $\mathrm{al}^{28}$ reported multiple hemangiomas of more than five lesions were associated with an increased risk of visceral involvement. Age at diagnosis in visceral vascular tumors was significantly younger than the age at diagnosis in cutaneous vascular tumors. This might be because of the small and asymptomatic lesions in the majority of patients with cutaneous vascular tumors and the aggressive nature of visceral vascular tumors, as well as complications associated with visceral involvement, especially in large sized visceral tumors, as those reported in this study were significantly larger in average size than the size of cutaneous vascular tumors.

KMP was reported in $71 \%$ of the patients with $\mathrm{KHE},{ }^{29}$ compared with $100 \%$ in this study. KHE without cutaneous involvement presented with retroperitoneal mass was likely to involve KMP and be complicated with congestive heart failure, bleeding, and abdominal complications. $^{29,30}$ Treatment options with a favorable outcome for KMP are consisting of vincristine monotherapy, ${ }^{30}$ prednisolone, methylprednisolone, ${ }^{8}$ propranolol, ${ }^{31}$ interferon- $\alpha$, sirolimus, ${ }^{13,32}$ and combined vincristine with an oral corticosteroid. ${ }^{8}$ Likewise, in this study, KHE with KMP patients were in complete remission and survived without disease recurrence.

Almost all patients with vascular tumors enrolled in this study survived with or without evidence of disease. One significant influential factor associated with outcomes was the size of the lesion at diagnosis, in which the tumor size among patients who survived with residual disease was significantly greater than the size of those who survived without disease. This result affirmed the finding reported by Akcay et $\mathrm{al}^{33}$ and Haggstrom et al, ${ }^{23}$ that the size of the hemangioma was a significant factor to predict disease complications, regardless of visceral involvement or types of treatment.

However, there are few pediatric vascular tumor studies of Asian-Pacific populations such as Chinese ${ }^{20}$ and Japanese. ${ }^{19}$ Thus, to our knowledge, this is the first pediatric vascular tumor study in South-East Asia.

The limitations of this study included the study design of a retrospective chart review from a single institution.
However, the uncommonness of the tumors operated on in a specific group of the pediatric population who obtained surgical intervention or followed at pediatric hematology and oncology clinic constituted a major restriction to conduct the prospective study. In addition, most of the patients, who were followed at dermatology or plastic surgery clinics and had never been evaluated in the pediatric department, might have been missed. This could explain many of the small size hemangiomas in older age patients, the lack of data of laser or topical medicines, and congenital hemangioma, which is common in this study. A future large multicenter study enrolling patients in all departments involved in patient's care, including pediatric, dermatology, and plastic surgery departments would be beneficial to improve the quality of data and truly represent pediatric vascular tumors in Thailand.

\section{Conclusion}

This study affirmed that hemangioma was the most common vascular tumor among children. Age at diagnosis in cutaneous vascular tumors was significantly older than visceral vascular tumors, which could be secondary to the significantly larger size of vascular tumors at initial presentation. Bleeding was the most common complication manifested at diagnosis. The outcomes were satisfactory with no treatment-associated mortality. In addition, the size of the tumor was the most influential factor to predict treatment outcomes among those patients.

\section{IRB Number: IRBRTA 959/2562}

Thai Clinical Trials Registry number: TCTR20190917001.

\section{Abbreviations}

CI, confidence interval; CT, computed tomography; ISSVA, International Society for the Study of Vascular Anomalies; ITP, immune thrombocytopenia; JNA, juvenile nasal angiofibroma; KHE, kapasiform hemangioendothelioma; KMP, Kasabach-Merritt phenomenon; MRI, magnetic resonance imaging; OR, odds ratio; $\mathrm{SD}$, standard deviation.

\section{Data Sharing Statement}

The datasets generated and/or analyzed during the current study are not publicly available since these datasets are being used in a different ongoing study. However, some datasets are provided as a supplementary table and data are available from the corresponding author on reasonable request. 


\section{Ethics Approval and Consent to Participate}

Written informed consent and assent forms to participate in the study were obtained from all participating subjects, including children, their parents, or legal guardians before initiation of patient's clinical data collection. This clinical study was approved by the Institutional Review Board, Royal Thai Army Medical Department (IRBRTA 959/ 2562) according to the ethical principles of the Declaration of Helsinki (1975), including its revision.

\section{Consent for Publication}

Written informed consent and assent forms for publication were obtained from the patients and parents before initiation of patients' clinical data collection.

\section{Acknowledgments}

The authors gratefully acknowledged Mrs. Supak Cae-Ngow, Office of Research and Development, Phramongkutklao Hospital and Phramongkutklao College of Medicine for statistical analysis.

\section{Author Contributions}

All authors made a significant contribution to the work reported, whether that is in the conception, study design, execution, acquisition of data, analysis and interpretation, or in all these areas; took part in drafting, revising, or critically reviewing the article; gave final approval of the version to be published; have agreed on the journal to which the article has been submitted; and agree to be accountable for all aspects of the work.

\section{Funding}

The funding from the Phramongkutklao College of Medicine and Hospital, Royal Thai Army was used to conduct the study, analyze and interpret the study results and submit the study for publication.

\section{Disclosure}

The authors declare that they have no competing interests.

\section{References}

1. Kilcline C, Frieden IJ. Infantile hemangiomas: how common are they? A systematic review of the medical literature. Pediatr Dermatol. 2008;25 (2):168-173. doi:10.1111/j.1525-1470.2008.00626.x

2. ISSVA Classification of Vascular Anomalies (C2018 International Society for the Study of Vascular Anomalies. www.issva.org. Available from: http://www.issva.org/classification. Accessed December 14, 2020.
3. Rubinstein JC, Christison-Lagay ER. Successful treatment of visceral infantile hemangioma of the omentum and mesentery with propranolol. J Pediatric Surgery Case Rep. 2014;2(6):302-304. doi:10.1016/j.epsc.2014.06.004

4. Adams DM, Brandao LR, Peterman CM, et al. Vascular anomaly cases for the pediatric hematologist oncologists-An interdisciplinary review. Pediatr Blood Cancer. 2018;65:1. doi:10.1002/pbc.26716

5. Mahajan P, Margolin J, Iacobas I. Kasabach-merritt phenomenon: classic presentation and management options. Clin Med Insights Blood Disord. 2017;10:1179545X17699849. doi:10.1177/1179545X17699849

6. Sepulveda A, Buchanan EP. Vascular tumors. Semin Plast Surg. 2014;28(2):49-57. doi:10.1055/s-0034-1376260

7. Lopez-Gutierrez JC. Current management of vascular tumors in the neonate. Curr Pediatr Rev. 2015;11(3):226-232. doi:10.2174/ 1573396311666150714105944

8. Drolet BA, Trenor CC 3rd, Brandao LR, et al. Consensus-derived practice standards plan for complicated Kaposiform hemangioendothelioma. $\quad J \quad$ Pediatr. $\quad$ 2013;163(1):285-291. doi:10.1016/j.jpeds.2013.03.080

9. Liu XH, Li JY, Qu XH, et al. Treatment of kaposiform hemangioendothelioma and tufted angioma. Int $J$ Cancer. 2016;139 (7):1658-1666. doi:10.1002/ijc.30216

10. Arneja JS, Pappas PN, Shwayder TA, et al. Management of complicated facial hemangiomas with beta-blocker (propranolol) therapy. Plast Reconstr Surg. 2010;126(3):889-895. doi:10.1097/ PRS.0b013e3181e5f8b6

11. Leaute-Labreze C, Hoeger P, Mazereeuw-Hautier J, et al. A randomized, controlled trial of oral propranolol in infantile hemangioma. $N$ Engl J Med. 2015;372(8):735-746. doi:10.1056/NEJMoa1404710

12. Sirachainan N, Lekanan W, Thammagasorn Y, Wanitkun S, Kadegasem P, Chunharas A. Response to propranolol in infantile hemangioma. Pediatr Int. 2016;58(7):662-665. doi:10.1111/ped.12992

13. Hammill AM, Wentzel M, Gupta A, et al. Sirolimus for the treatment of complicated vascular anomalies in children. Pediatr Blood Cancer. 2011;57(6):1018-1024. doi:10.1002/pbc.23124

14. Hu H, Song P, Yang J, Wang X, Chen Z, Fang J. Therapeutic effect of high-frequency ultrasound-assisted dye laser on hemangioma and its influence on serum HIF-1alpha in patients. J Clin Lab Anal. 2020;34 (1):e22970. doi:10.1002/jcla.22970

15. Young RJ, Brown NJ, Reed MW, Hughes D, Woll PJ. Angiosarcoma. Lancet Oncol. 2010;11(10):983-991. doi:10.1016/S1470-2045(10) 70023-1

16. David Osifo O, Evbuomwan I. Hemangiomas in children: challenges and outcome of surgical management in benin city, Nigeria. Iran J Pediatr. 2011;21(3):350-356.

17. Hoornweg MJ, Smeulders MJ, Ubbink DT, van der Horst CM. The prevalence and risk factors of infantile haemangiomas: a case-control study in the Dutch population. Paediatr Perinat Epidemiol. 2012;26 (2): $156-162$.

18. Bauland CG, Luning TH, Smit JM, Zeebregts CJ, Spauwen PH. Untreated hemangiomas: growth pattern and residual lesions. Plast Reconstr Surg. 2011;127(4):1643-1648. doi:10.1097/ PRS.0b013e318208d2ac

19. Kawaguchi A, Kunimoto K, Inaba Y, et al. Distribution analysis of infantile hemangioma or capillary malformation on the head and face in Japanese patients. J Dermatol. 2019;46(10):849-852. doi:10.1111/ 1346-8138.15051

20. Niu HL, Zhou SY, Lin QQ, et al. [Clinicopathologic study of pediatric vascular anomalies: a report of 117 cases]. Zhonghua Bing Li Xue Za Zhi. 2016;45(4):252-257. doi:10.3760/cma.j.issn.0529-5807.2016.04.008

21. Johnson EF, Davis DM, Tollefson MM, Fritchie K, Gibson LE. Vascular tumors in infants: case report and review of clinical, histopathologic, and immunohistochemical characteristics of infantile hemangioma, pyogenic granuloma, noninvoluting congenital hemangioma, tufted angioma, and kaposiform hemangioendothelioma. Am J Dermatopathol. 2018;40 (4):231-239. doi:10.1097/DAD.0000000000000983 
22. Beck DO, Gosain AK. The presentation and management of hemangiomas. Plast Reconstr Surg. 2009;123(6):181e-191e. doi:10.1097/PRS.0b013e3181a65c59

23. Haggstrom AN, Drolet BA, Baselga E, et al. Prospective study of infantile hemangiomas: clinical characteristics predicting complications and treatment. Pediatrics. 2006;118(3):882-887. doi:10.1542/ peds.2006-0413

24. Munden A, Butschek R, Tom WL, et al. Prospective study of infantile haemangiomas: incidence, clinical characteristics and association with placental anomalies. Br J Dermatol. 2014;170(4):907-913. doi:10.1111/bjd.12804

25. Chiller KG, Passaro D, Frieden IJ. Hemangiomas of infancy: clinical characteristics, morphologic subtypes, and their relationship to race, ethnicity, and sex. Arch Dermatol. 2002;138(12):1567-1576. doi:10.1001/archderm.138.12.1567

26. Bertrand J, McCuaig C, Dubois J, Hatami A, Ondrejchak S, Powell J. Propranolol versus prednisone in the treatment of infantile hemangiomas: a retrospective comparative study. Pediatr Dermatol. 2011;28(6):649-654. doi:10.1111/j.1525-1470.2011.01551.x

27. Kollipara R, Odhav A, Rentas KE, Rivard DC, Lowe LH, Dinneen L. Vascular anomalies in pediatric patients: updated classification, imaging, and therapy. Radiol Clin North Am. 2013;51(4):659-672. doi:10.1016/j.rcl.2013.04.002
28. Chang LC, Haggstrom AN, Drolet BA, et al. Growth characteristics of infantile hemangiomas: implications for management. Pediatrics. 2008;122(2):360-367. doi:10.1542/peds.2007-2767

29. Croteau SE, Liang MG, Kozakewich HP, et al. Kaposiform hemangioendothelioma: atypical features and risks of Kasabach-Merritt phenomenon in 107 referrals. J Pediatr. 2013;162(1):142-147. doi:10.1016/j.jpeds.2012.06.044

30. Traivaree C, Lumkul R, Torcharus K, Krutuecho T, Sriphaisal T. Outcome of Kasabach-Merritt phenomenon: the role of vincristine as monotherapy: report of a case. J Med Assoc Thai. 2012;95(Suppl 5):S181-185.

31. Oksiuta M, Matuszczak E, Dębek W, Dzienis-Koronkiewicz E, Hermanowicz A. Successful exclusive propranolol therapy in an infant with life-threatening Kasabach-Merritt syndrome. J Pediatric Surgery Case Rep. 2013;1(8):200-202. doi:10.1016/j. epsc.2013.05.018

32. Wang Z, Li K, Dong K, Xiao X, Zheng S. Refractory Kasabach-Merritt phenomenon successfully treated with sirolimus, and a mini-review of the published work. J Dermatol. 2015;42 (4):401-404. doi:10.1111/1346-8138.12797

33. Akcay A, Karakas Z, Saribeyoglu ET, et al. Infantile hemangiomas, complications and follow-up. Indian Pediatr. 2012;49(10):805-809. doi:10.1007/s13312-012-0193-3

\section{Publish your work in this journal}

Pediatric Health, Medicine and Therapeutics is an international, peerreviewed, open access journal publishing original research, reports, editorials, reviews and commentaries. All aspects of health maintenance, preventative measures and disease treatment interventions are addressed within the journal. Practitioners from all disciplines are invited to submit their work as well as healthcare researchers and patient support groups. The manuscript management system is completely online and includes a very quick and fair peer-review system. Visit http://www.dovepress.com/testimonials.php to read real quotes from published authors. 